\title{
Breath odor characteristics after drinking alcoholic beverages and health monitoring
}

\author{
T. Oyabu \\ Kanazawa Seiryo University, Japan
}

\begin{abstract}
Alcohol concentration in the expiration of a subjective person after drinking was examined. Beer, Japanese sake, red wine and shoch $u$ were adopted as the alcoholic subjects. The sensor outputs after 1 hour and 2 hours of drinking were adopted in the technique. The concentration grade was indicated using three metal-oxide odor sensors. It became obvious that the alcoholic component in the expiration could remain over 3 hours after drinking. Japanese elderly people mostly prefer beer and sake according to a questionnaire survey which was carried out for the aged, and the number of people was 68 . The survey was carried out by a mail correspondence method. The number of males was 37 and the female number was 31. Many persons who received the questionnaire preferred beer and sake to whiskey and wine. In this study, the sensor-output characteristic as a function of passage of time after drinking sake was investigated and the suitable amount could be indicated by a developed technique. This means an amount of alcohol from which the subject feels refreshment of mind and body. In the questionnaire, it became obvious that $61 \%$ of aged men habitually drunk and $18 \%$ of females drunk. Women also preferred wine, plum liquor and shochu cocktails. This system was developed to survey the aged life style and identify whether they drunk moderately or not. And it can be also applicable to health monitoring for the elderly person.

Keywords: odor sensor, gas sensor, sensory system, welfare, the aged.
\end{abstract}

\section{Introduction}

Various kinds of problems are arising together with aging in Japan as well as other advanced countries. The important thing for the aged is to make a life worth living in quality. It is necessary to draw on our resources first and last to 
support the aged life style. Recently, it has been reported that the rate of illnesses are increasing due to drinking too much [1]. It is necessary from the health-care point of view that the aged limit themselves to moderate drinking. Many males drank both sake and beer. Over drinking could trigger off not only dementia and Alzheimer's disease but also hypertension and cerebrovascular accidents [2]. On the contrary, moderate drinking controls those diseases and has a positive effect on diabetes, heart disease, restraining cancer and health care [3]. It should be recommended that the aged keep a lifestyle of moderate drinking and it is also desired for the aged to live a full life [4]. However, the drinking amount has to be limited strictly and it is necessary to construct a system which can survey the drinking amount and the kind of alcohol.

In this study, an odor sensory system was constructed to check the alcohol concentration and its kind in the expiration using metal oxide odor-sensors [5]. Also the concentration and the kind of alcohol in the expiration were examined. As for the results, there were some distinctions in the odor characteristic of the expiration after drinking and the amount of sake could be estimated using the characteristics. The system can raise caution about drinking alcoholic beverages. To control drinking is to maintain one's good health. The system will work for healthcare.

\section{Experimental}

Three types of metal oxide odor sensors are adopted in this system to examine the odor components and the grade in the expiration of a subjective person. Those three sensors are called S1, S2 and S3. S1 and S2 are made from tin oxide. S3 is made from indium oxide [6]. These three sensors have different sensitivities to various types of reducing gases respectively. S1 and S2 have a high sensitivity to alcoholic gases. Especially S2 has higher sensitivity to the gases. S3 has a high sensitivity to hydrogen gas but has no sensitivity to alcoholic gases. The sensor is suitable to detect the strain and fatigue from a subjective expiration. These sensors were adopted to detect the fatigue after drinking. The three sensors are installed on the inside of the lid of a small glass container of $150 \mathrm{ml}$. The photograph of the three sensors is shown in Fig. 1. The photograph of the container installing the sensors is also shown in Fig. 2. The expiration was introduced into the container through a Teflon tube. The calibre is $2 \mathrm{~mm}$. The container also has an exhaust pipe of the same calibre.

The sensor outputs are indicated as a dc voltage of 0 to $5 \mathrm{~V}$ according to the odor grade and components in the expiration. The output becomes larger as the odor concentration becomes larger. The odor is a kind of reducing gas and the concentration is very low. In the experiment, the base levels of the three sensor outputs are measured for 30 seconds in the first stage. After that, the expiration is introduced into the container via the tube for five seconds. The sensor output increases immediately after the introduction. The output range between the base level and the level of 85 seconds later is called as "sensor output". It takes 120 seconds for each experiment. The time chart is indicated in Fig. 3. The sensor outputs show the characteristics one hour later after drinking sake. The output 
characteristic of S3 is low and the one of S2 is higher. The levels are measured every second and the data are input into the data logger through an A-D converter. After that, the data are inputted into a mobile computer. The program is written by $\mathrm{C}$-language.

A questionnaire was carried out to examine the relationship among the alcoholic volume, the kind and seniors' feelings of purpose in their life. The summary of questionnaire indicates that Japanese elderly people mostly prefer beer and sake. It was carried out for the aged and the number of people was 68 .

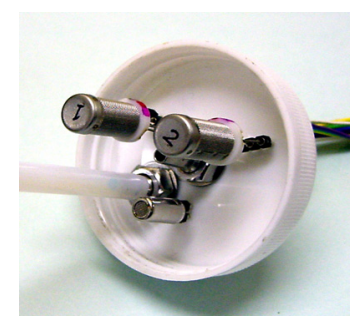

Figure 1: The photograph of the adopted three sensors.

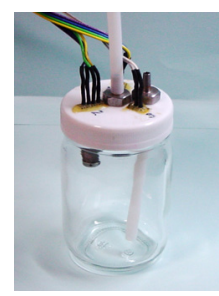

Figure 2: The glass container adopted in this experiment.

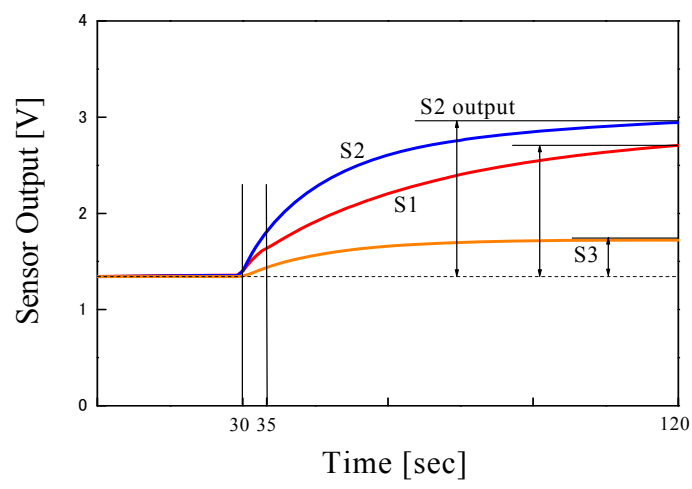

Figure 3: The experimental process for the detection of breath odor. 


\section{Results}

\subsection{Questionnaire for drinking}

The number of males was 37 and the females were 31 . The results for drinking habits are shown in Table 1. The person who drinks any kind of alcohol once or more a week belongs to "drinker". "Non-drinker" includes people who drink only on social occasions and people who did not drink at all. In this questionnaire, the purpose was to examine the population of the aged drinker and their favorite liquors. When someone drinks two types or more, he or she must indicate the most favorite one. In a questionnaire which we sent out, it became obvious that $61 \%$ of elderly men and $18 \%$ of elderly women drank habitually. As a result, the number of male drinkers exceeded three times of females. The favorite drinks were beer and sake for male. Females like sake and beer but they also drink other kinds of alcohols such as wine and shochu. The results for the favorite drinks are shown in Table 2. The suitable quantity for one's health was also surveyed and the results are shown in Table 3 . The quantity of beer was a

Table 1: $\quad$ Drinking percentage by a questionnaire.

\begin{tabular}{lcc}
\hline & Male (\%) & Female (\%) \\
\hline Drinker & 61 & 18 \\
Non-drinker & 39 & 82 \\
\hline
\end{tabular}

Table 2: $\quad$ The percentage of the aged favorite alcohol.

\begin{tabular}{lcc}
\hline & Male (\%) & Female (\%) \\
\hline Beer & 48 & 37 \\
Sake & 43 & 35 \\
Whiskey & 5 & 1 \\
Other & 4 & 27 \\
\hline
\end{tabular}

Table 3: $\quad$ The suitable amounts of liquors declared by the aged.

\begin{tabular}{|c|c|}
\hline & $\begin{array}{l}\text { Suitable amount } \\
(\mathrm{ml})\end{array}$ \\
\hline Beer & 250 \\
\hline Sake & 180 \\
\hline Whiskey & 90 \\
\hline Red wine & 180 \\
\hline Shochu & 90 \\
\hline
\end{tabular}


volume of a regular-can of $250 \mathrm{ml}$ and the sake was one "go" which meant $180 \mathrm{ml}$. In Japan, the quantity of sake and beer is measured using the unit of "go". There were no sexual distinctions in the suitable quantity. It is thought that the quantity is fairly restricted according to their earnings and health care.

\subsection{Breath odor characteristic for alcohol}

Alcohol components are contained in expiration for over three hours after the subject drank liquor. The kind of liquor can be identified with the use of three sensor outputs. It can also check whether the drinking quantity is suitable or not. The system will adopt the amount based on Table 3. The breath odor experiments were carried out while referring to the results of the questionnaire. The subject was a poor drinking male of 55 years old. He was an acquaintance, having deep understanding and consciousness of the problems for the aged. $\mathrm{He}$ could operate the system.

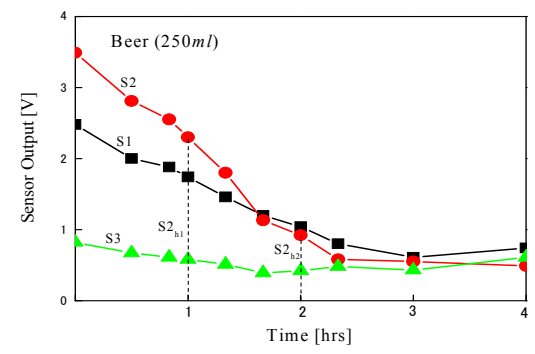

Figure 4: The sensor outputs for the expiration when the subject drunk a beer of $250 \mathrm{ml}$.

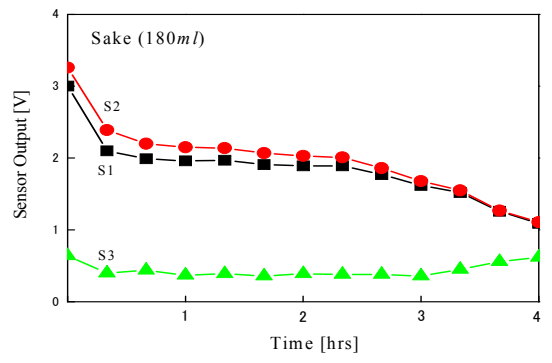

Figure 5: The sensor outputs for the expiration of the subject who drunk a sake of $180 \mathrm{ml}$.

The three sensor-output characteristics for expiration after the subject drank a beer of $250 \mathrm{ml}$ are indicated in Fig. 4. The horizontal axis means the passage of time and the vertical axis means the sensor output. The figure indicates that the outputs decrease gradually as the time progresses. The characteristic returned to the original level two and half hours later after drinking. The characteristics of 
the sensor outputs when the subject drinks sake of $180 \mathrm{ml}$ are shown in Fig. 5. The characteristics differ from the ones in Fig. 4 and do not decrease over three hours. It took about four hours until they return to the original levels respectively. It takes a long time before the sensor level returns to the original level when the subject drinks sake. This is a feature of sake. The same feature appeared when the subject drank sake of $135 \mathrm{ml}$ but was not apparent in the case of $90 \mathrm{ml}$ and under. The result of whiskey is indicated in Fig. 6. The characteristics are very similar with the ones of Fig. 4. The characteristics for red wine of $120 \mathrm{ml}$ and shochu of $40 \mathrm{ml}$ are indicated in Figs. 7 and 8 . The characteristics for popular drinks are shown in Figs. 4 to 8. In Japan, there is a tendency that the aged habitually drink sake. Therefore, the characteristics for the amount of sake were examined. The results are shown in Fig. 9. The experiments were carried out for the amounts of 45, 90, 135 and $180 \mathrm{ml}$. In Fig. 9, figure (a) means S1 characteristics, (b) means S2 and (c) means S3.The $\mathrm{S} 3$ characteristics are unrelated to the drinking amount of sake. This sensor is used to detect fatigue and stress. In Fig. 9, the outputs at 1 and 2 hours become higher

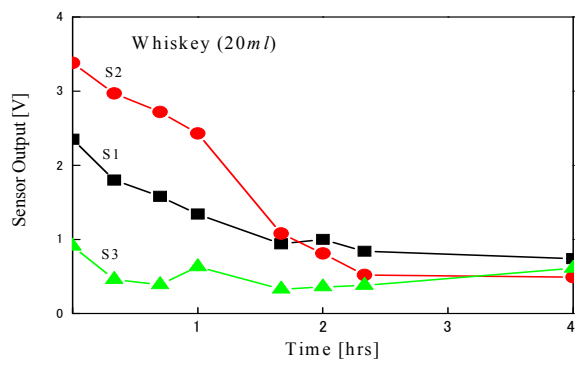

Figure 6: The sensor outputs for the expiration of the subject who drunk a whiskey of $20 \mathrm{ml}$.

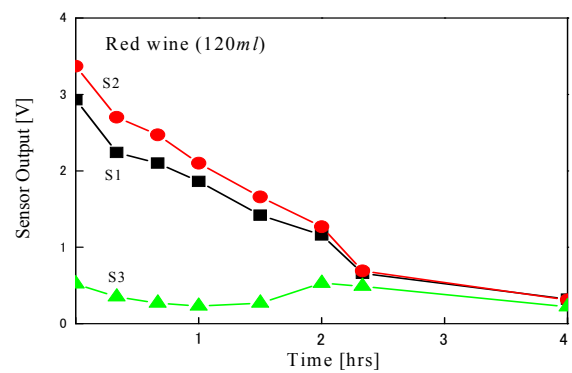

Figure 7: The sensor outputs for the expiration of the subject who drunk a red wine of $120 \mathrm{ml}$. 


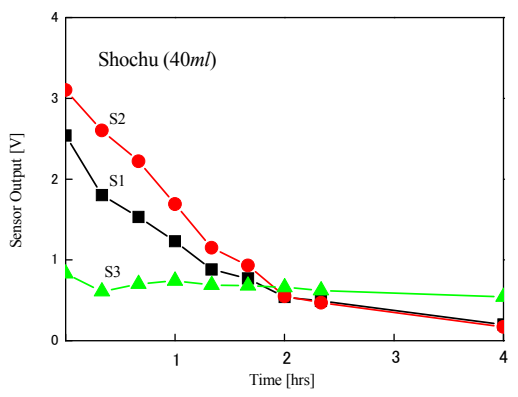

Figure 8: The sensor outputs for the expiration of the subject who drunk a shochu of $40 \mathrm{ml}$. It is a clear distilled liquor.
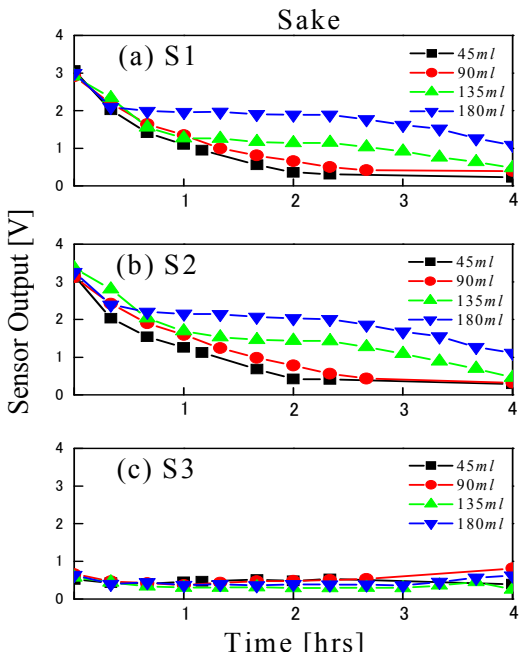

Figure 9: The three sensor outputs changes as a function of the sake quantity. (a) means S1 output, (b) means S2 output and (c) means S3 output.

when the subject drinks larger amounts of sake. There is a possibility to distinguish the drinking amount using their outputs. The S2 level reaches above $3 \mathrm{~V}$ when the subject drinks alcohol. By examining the S2 level, the system can distinguish whether the subject drunk liquor or not. If the S2 level reaches over $3 \mathrm{~V}$, it is considered that the subject drunk liquor. The $\mathrm{S} 2$ outputs at 1 hour $\left(\mathrm{S} 2_{\mathrm{h} 1}\right)$ and at 2 hours $\left(\mathrm{S} 2_{\mathrm{h} 2}\right)$ were adopted as parameters to distinguish the kind of liquor.

\subsection{Distinction of the alcoholic type and its amount}

The distinctive possibility of alcohol type and its amount was already expressed in the section 3.2. In this section, we adopt a new parameter $\mathrm{w}=\mathrm{S} 2_{\mathrm{h} 1}-\mathrm{S} 2_{\mathrm{h} 2}$. The scattering diagram between $\mathrm{S} 2_{\mathrm{h} 2}$ and $\mathrm{w}$ are exhibited in Fig. 10. 
The horizontal axis is $\mathrm{S}_{\mathrm{h} 2}$ and vertical axis is $\mathrm{w}$. The sensor output for whiskey and beer at one hour are high but remarkably reduce two hours later. In sake experiments for 135 and $180 \mathrm{ml}$, the differences between $\mathrm{S} 2_{\mathrm{h} 1}$ and $\mathrm{S} 2_{\mathrm{h} 2}$ are small. So it is thought that the alcohol components are not lost in the expiration for three hours after drinking. According to the declaration, the subject felt himself warm when drinking sake of 135 and $180 \mathrm{ml}$, and his thinking faculty slightly deteriorated. He felt relaxed with the drinking of red wine, sake of 45 and $90 \mathrm{ml}$ and shochu of $40 \mathrm{ml}$. Therefore, it is thought that the suitable quantity range of the subject is $\mathrm{w}=0.5$ to 1.25 . The $\mathrm{w}$ moves downwards as the sake quantity increases. It is thought that there is a correlation between the parameters

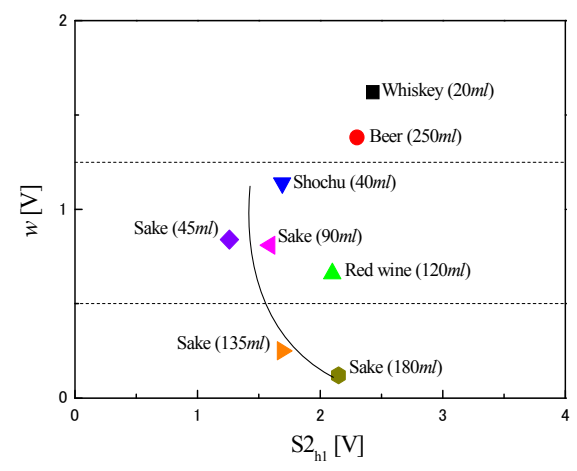

Figure 10: Scattering diagram of $\mathrm{S}_{\mathrm{h} 1}$ and $\mathrm{w}$ for the tested alcohol.

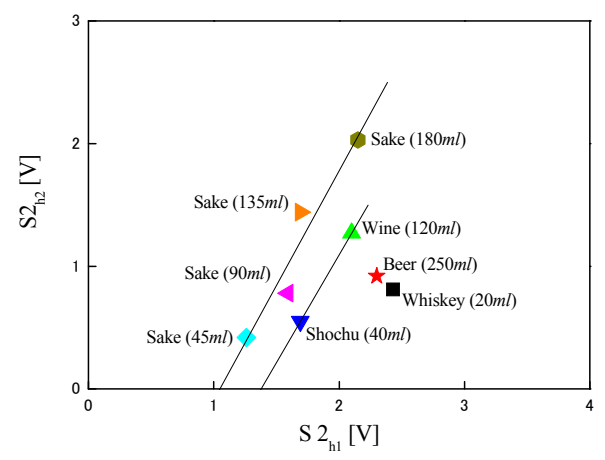

Figure 11: Scattering diagram of $\mathrm{S}_{\mathrm{h} 1}$ and $\mathrm{S} 2_{\mathrm{h} 2}$ for the tested alcohol.

$\mathrm{S} 2_{\mathrm{h} 1}$ and $\mathrm{S} 2_{\mathrm{h} 2}$ according to the amount of drinking. The scatter diagram of $\mathrm{S} 2_{\mathrm{h} 1}$ and $\mathrm{S} 2_{\mathrm{h} 2}$ for tested alcohol is shown in Fig. 11. As for the result, the plots for sake are on a straight line and the amount can be identified using this line. The plots for wine and shochu are also on a line. The plots for beer and whiskey had a different characteristic. Some plots are examined in addition. 


\subsection{Daily fluctuation of sensor outputs for human behaviors}

The sensors have different responses to the expiration right after eating, drinking and teeth brushing. The breath odor grade becomes larger according to physical condition and illnesses. It is desirable for the aged to have a life worth living and moreover they spend a comfortable and healthy life. The system which can detect those conditions is very effective. In this study, the daily odor-sensor output changes for some human behaviors are examined. The results are shown in Fig. 12. The experiment was carried out on a holiday. The rising hour was 7:40 and bed time was 22:00. But he watched TV in the bed and slept at about 11:30. He played a tennis game from 9:15 to 10:30 and took a hot-spring bath from 18:50 to19:20. He declared that he had spent a relaxed day. He drunk a sake of $90 \mathrm{ml}$ and the sensor responses for the behaviors were measured at 16:00, 17:00 and 18:00 respectively. Fig. 12(a) is for S1, (b) is for S2 and (c) is for S3. The breath odor is somewhat higher at awakening and S3 output is at a higher level than the average of 0.62. The averages for S1 and S2 are 0.99 and 1.13. These averages of S1 and S2 become higher when the subject drinks alcohol. When the subject did not drink, the one of S2 was about 0.8. S3 output is almost

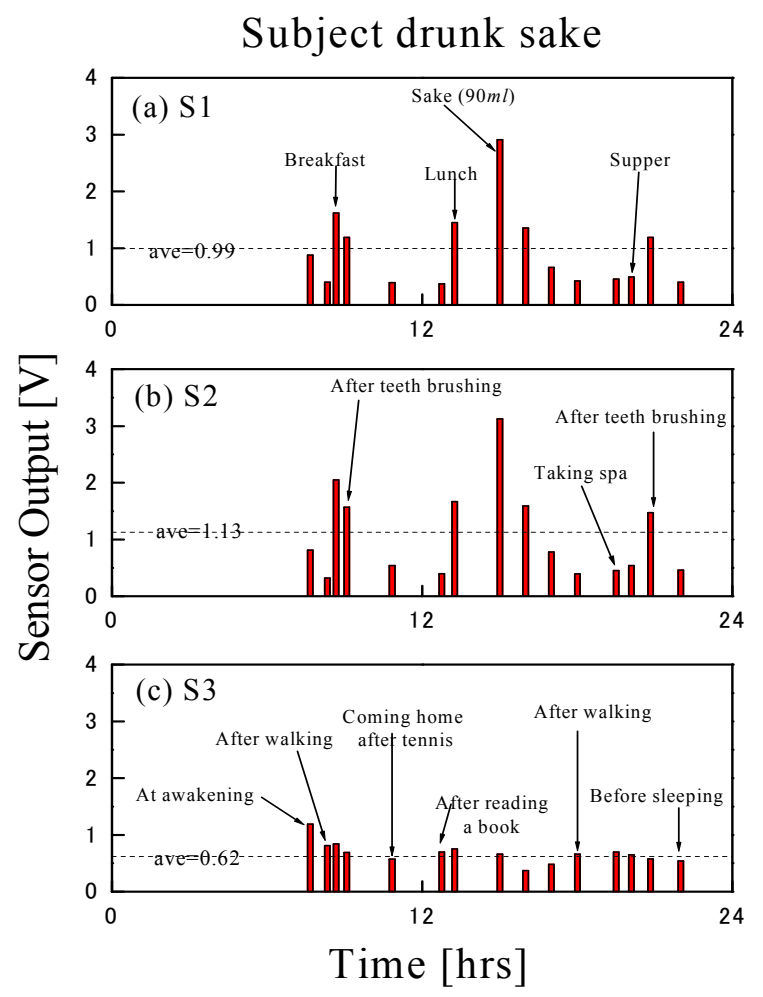

Figure 12: The daily fluctuations of the adopted three sensors for various kinds of human behaviors. 
constant through the day, though it is somewhat higher at awakening. We can understand the living style of the aged at a distance by sending the data into the Internet. It is also necessary to establish the identification technique of the style using sensor output characteristics.

\section{Conclusion}

It has been reported that drinking a moderate amount of alcohol has a positive effect on the health of the aged. The questionnaire on drinking for the aged was sent out for this study. Especially the rate of drinking and their favorite kinds of alcohol were examined. As for the results, the rates were $61 \%$ for male and $18 \%$ for female. And the favorite liquors were beer and sake. Females, however, like various kinds of drinks, for instance wine, plum liquor and shochu cocktails. The expiration was examined after drinking beer, sake, whiskey, red wine and shochu. It became obvious that the adopted subject relaxed when he drunk sake of $90 \mathrm{ml}$, red wine of $120 \mathrm{ml}$ and shochu of $40 \mathrm{ml}$. He declared that his thinking ability fell off slightly when he drank sake of over $135 \mathrm{ml}$, beer of over $250 \mathrm{ml}$ and whiskey of over $20 \mathrm{ml}$. These ranges were plotted in Fig. 10 using sensor outputs.

The investigation on the relationship between health care and drinking customs will be studied hereafter. And an odor system, which can survey the life of the aged and support their living style, will be also built. This system can be connected to the Internet. The standardized sensor data which includes the bit size and assignment of data are also considered.

\section{References}

[1] Kishi, R., Kono, S., Omae, K. \& Koizumi, A., NEW Preventive Medicine and Public Health, Nanko-do: Tokyo, p146, 2006 (in Japanese)

[2] Yanagawa, H., Basic Learning of Health Management, Nanko-do: Tokyo, p114, 2006 (in Japanese)

[3] Muramatsu, T. \& Kajimoto, M., Public Health, Kodan-sya: Tokyo, pp.56-57, 2005 (in Japanese)

[4] Sawada, A., Oyabu, T., Seto, S. \& Katsube, T., Survey system for life styles of the elderly and to identify the consumption of food and drink, Environmental Health Risk IV, WIT PRESS: Southampton, pp.61-70, 2007

[5] Oyabu, T., Okada, A., Manninen, O. \& Lee, Duck-Dong., Proposition of a survey device with odor sensors for an elderly person, Sensors \& Actuators B, 96, pp.239-244, 2003.

[6] Oyabu, T., Okada, A., Manninen, O., Lee, D. D., Proposition of a survey device with odor sensors for an elderly person, Sensors \& Actuators B, 96, pp.239-244, 2003. 